\title{
Is combined use of intravenous and intraarticular tranexamic acid superior to intravenous or intraarticular tranexamic acid alone in total knee arthroplasty? A meta-analysis of randomized controlled trials
}

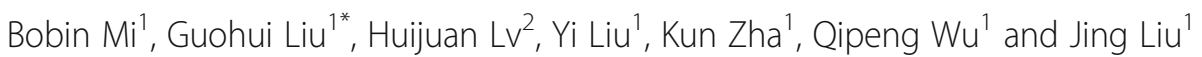

\begin{abstract}
Background: Tranexamic acid (TXA) has been proven to be effective in reducing blood loss and transfusion rate after total knee arthroplasty (TKA) without increasing the risk of deep vein thrombosis (DVT) and pulmonary embolism (PE). Recently, an increasing number of studies have been interested in applying combined intravenous (IV) with intraarticular (IA) tranexamic acid in total knee arthroplasty. The purpose of this meta-analysis was to compare the blood loss and complications of combined TXA with IV TXA or IA TXA on TKA.

Methods: Systematic search of literatures were conducted to identify related articles that were published in PubMed, MEDLINE, Embase, the Cochrane Library, SpringerLink, ClinicalTrials.gov, and Ovid from their inception to September 2016. All studies that compare blood loss and complications of combined TXA and IV TXA or IA TXA on TKA were included. Main outcomes were collected and analyzed by the Review Manager 5.3.

Results: Five studies were included in the present meta-analysis. There was significant difference in total blood loss and blood volume of drainage when compared combined TXA group with IV TXA group or IA TXA group $(P<0.05)$. There was no difference in transfusion rate and thromboembolic complications when comparing combined TXA with IV TXA or IA TXA alone $(P>0.05)$.
\end{abstract}

Conclusions: Compared with administration of IA TXA or IV TXA alone on TKA, combined use of TXA has advantages in reducing total blood loss and blood volume of drainage without increasing the incidence of thromboembolic complications. We recommend combined TXA as the preferred option for patients undergoing TKA.

Keywords: Tranexamic acid, Combined, Intravenous, Intraarticular, Total knee arthroplasty

\footnotetext{
* Correspondence: liuguohui@medmail.com.cn

'Department of Orthopedics, Union Hospital, Tongji Medical College,

Huazhong University of Science and Technology, 1277, Jiefang Avenue,

Wuhan, China

Full list of author information is available at the end of the article
} 


\section{Background}

As the number of patients who were afflicted with osteoarthritis (OA) is steadily increasing, the surgical volume of primary total knee arthroplasty (TKA) is increasing as well [1]. However, primary TKA is closely associated with the increase of total blood loss and transfusion rate. Some studies reported that the total blood loss can reach to $1500 \mathrm{~mL}$ and $60 \%$ of patients need allogeneic blood transfusion [2, 3]. Massive blood transfusion requirements in TKA increased the risks of allergic reaction, immune response, cost, and infection [4, 5]. Various blood-conserving techniques have been used to reduce blood transfusion, including controlled hypertension, tourniquet, and tranexamic acid (TXA) [6-8].

It has been widely accepted that patients undergoing TKA have an increased risk of perioperative bleeding [9]. TXA is an antifibrinolytic drug that inhibits the activation of plasminogen so as to decrease the amount of blood loss [10]. TXA can be applied by the intravenous (IV) or the intraarticular (IA) route. However, to achieve the maximum plasma concentration, TXA takes about 5-15 min for IV administration and $30 \mathrm{~min}$ for IA administration. Thus, IV administration is a rapid route for patients to increase the therapeutic concentration of TXA. Then, an increasing number of studies began to pay close attention on the effect of IV TXA on TKA $[11,12]$. It was reported that IV TXA decreased perioperative bleeding and caused a reduction in total blood loss by up to $32 \%$. Compared with IV TXA, the IA TXA has some advantages, such as easy administration, providing a maximum concentration of TXA at the bleeding site and inhibiting local activation of fibrinolysis [13]. Recent studies have confirmed that the administration of TXA, which is used directly into the surgical wound, reduced postoperative bleeding from 20 to $25 \%$ [13].

Recently, more and more studies tended to use combined TXA instead of using IV or IA TXA alone [14, 15]. It was shown that this method (combined TXA) can effectively reduce the amount of bleeding after TKA. Nevertheless, these studies reported inconsistent results of comparing combined TXA with IV or IA TXA alone on TKA [15-17]. Therefore, this meta-analysis was designed to compare the effectiveness and safety of combined TXA with IV TXA or IA TXA for patients undergoing primary TKA through evaluating the total blood loss, blood volume of drainage, transfusion rate, and thromboembolic complications.

\section{Methods}

\section{Search strategy}

Articles were searched in the following databases from their inception to September 2016: PubMed, MEDLINE, Embase, the Cochrane Library, SpringerLink, ClinicalTrials.gov, and Ovid. The following search terms were used: tranexamic acid or TXA or topical tranexamic acid or topical TXA or intraarticular tranexamic acid or IA TXA or intravenous tranexamic acid or IV TXA or total knee arthroplasty or TKA or total knee replacement or TKR.

\section{Data selection}

To evaluate eligibility for inclusion, two investigators screened the title and abstracts of the articles independently. Any disagreements were resolved by discussion among the authors. A third researcher was the adjudicator when there were debates between two investigators. Articles should meet the following criteria: (1) the studies should be designed as RCTs, (2) the participants should be at least 18 years old, (3) the articles should be comparing the combined TXA with IV or IA TXA, and (4) the articles were restricted to English language.

\section{Data extraction}

Two authors independently extracted the following data from each eligible study: study design, type of study population, age, number of participants, and interventions. Discrepancies were resolved by a third investigator.

\section{Quality and risk of bias assessments}

The modified Jadad scale was used to assess the methodological quality of each study. A score of $\geq 4$ indicates high quality. The Cochrane Handbook for Reviews of Interventions (RevMan Version 5.3) was used to assess the risk of bias. Two authors subjectively reviewed all articles and assigned a value of "high," "low," or "unclear" based on the following: selection bias, performance bias, detection bias, attrition bias, reporting bias, and other bias. Any disagreements were resolved by discussion and consensus. In order to improve accuracy, a third investigator was consulted when any disagreement emerged.

\section{Statistical analysis}

RevMan software was used to analyze the data from included studies. For binary data, risk ratio (RR) and 95\% confidence interval (CI) were assessed ( $\alpha=0.05$ for the inspection standards). For continuous data, means and standard deviations were pooled to a weighted mean difference (WMD) and 95\% confidence internal (CI) in the meta-analysis. Heterogeneity was tested using the $I^{2}$ statistic. Studies with an $I^{2}$ statistic of 25 to $50 \%$ were considered to have low heterogeneity. Those with an $I^{2}$ statistic of 50 to $75 \%$ were considered to have moderate heterogeneity. Those with an $I^{2}$ statistic $>75 \%$ were considered to have high heterogeneity. When the $I^{2}$ statistic was $>50 \%$, sensitivity analyses were performed to identify the potential sources of heterogeneity [18]. Statistical significance was indicated by a $P$ value $<0.05$. 


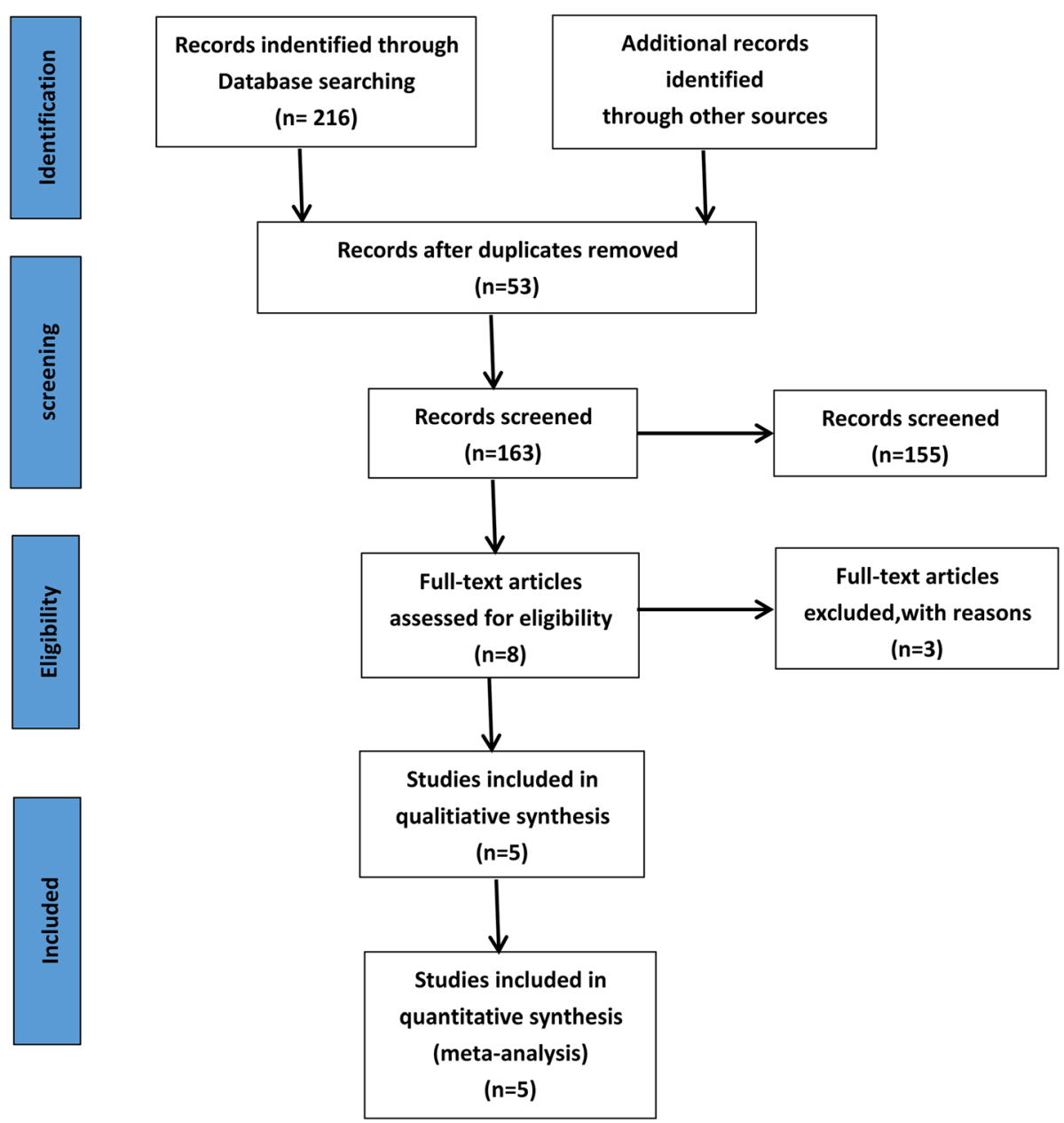

Fig. 1 Flow chart showing study identification, inclusion, and exclusion

\section{Results}

Description of studies and demographic characteristics As shown in Fig. 1, a total of 216 articles were identified as potentially relevant studies. According to the agreed criteria, subsequent scrutiny leads to the exclusion of 208 citations. Full publications were obtained for eight citations: these were assessed and three further citations were excluded, leaving five trials included in the meta-analysis. The demographic characteristics were summarized in Tables 1 and 2. Among them, three trials
$[15,17,19]$ compared the effect of the combined TXA group with the IV TXA group, one trial [16] compared the combined TXA group with the IA TXA group, one trial [20] compared the combined TXA group with both the IA TXA group and the IA TXA group, respectively.

\section{Risk of bias in included studies}

The assessment of risk of bias was presented in the "Risk of bias assessment of included studies" (Fig. 2). All trials were described as randomized trial design. One trial [15]

Table 1 The characteristics of included studies

\begin{tabular}{|c|c|c|c|c|c|c|c|c|c|c|c|}
\hline \multirow[t]{2}{*}{ Study } & \multirow[t]{2}{*}{ Year } & \multirow[t]{2}{*}{ Country } & \multicolumn{3}{|c|}{ Patients $(n)$} & \multicolumn{3}{|l|}{ Age (years) } & \multirow{2}{*}{$\begin{array}{l}\text { Study } \\
\text { design }\end{array}$} & \multirow[t]{2}{*}{ Diagnosis } & \multirow{2}{*}{$\begin{array}{l}\text { Quality } \\
\text { score }\end{array}$} \\
\hline & & & C & IA & IV & C & IA & IV & & & \\
\hline Huang ZY & 2014 & China & 92 & & 92 & $65.4 \pm 8.7$ & & $64.7 \pm 9.5$ & $\mathrm{RCT}$ & $\mathrm{OA}$ & 4 \\
\hline Jain NP & 2016 & India & 59 & & 60 & $68.2 \pm 8.66$ & & $70.0 \pm 6.56$ & $\mathrm{RCT}$ & $\mathrm{OA}$ & 5 \\
\hline Lin SY & 2015 & Taiwan & 40 & 40 & & $70.7 \pm 8.2$ & $71.0 \pm 7.2$ & & $\mathrm{RCT}$ & $\mathrm{OA}$ & 4 \\
\hline Nielsen CS & 2016 & Denmark & 30 & & 30 & $65.5 \pm 7.8$ & & $63.2 \pm 8.6$ & $\mathrm{RCT}$ & $\mathrm{OA}$ & 7 \\
\hline Song EK & 2016 & Korea & 50 & 50 & 50 & $70.8 \pm 6.8$ & $69.8 \pm 6.8$ & $69.2 \pm 6.4$ & $\mathrm{RCT}$ & $\mathrm{OA}$ & 7 \\
\hline
\end{tabular}




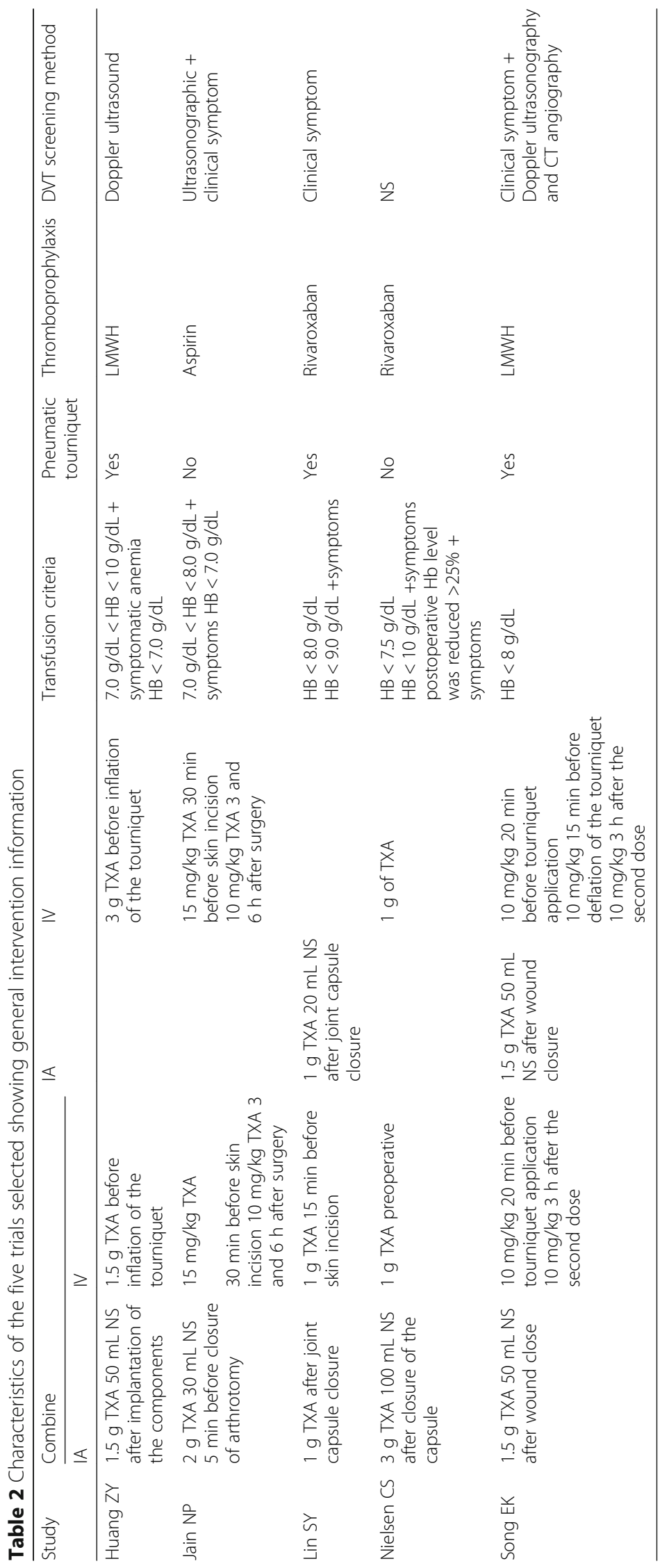




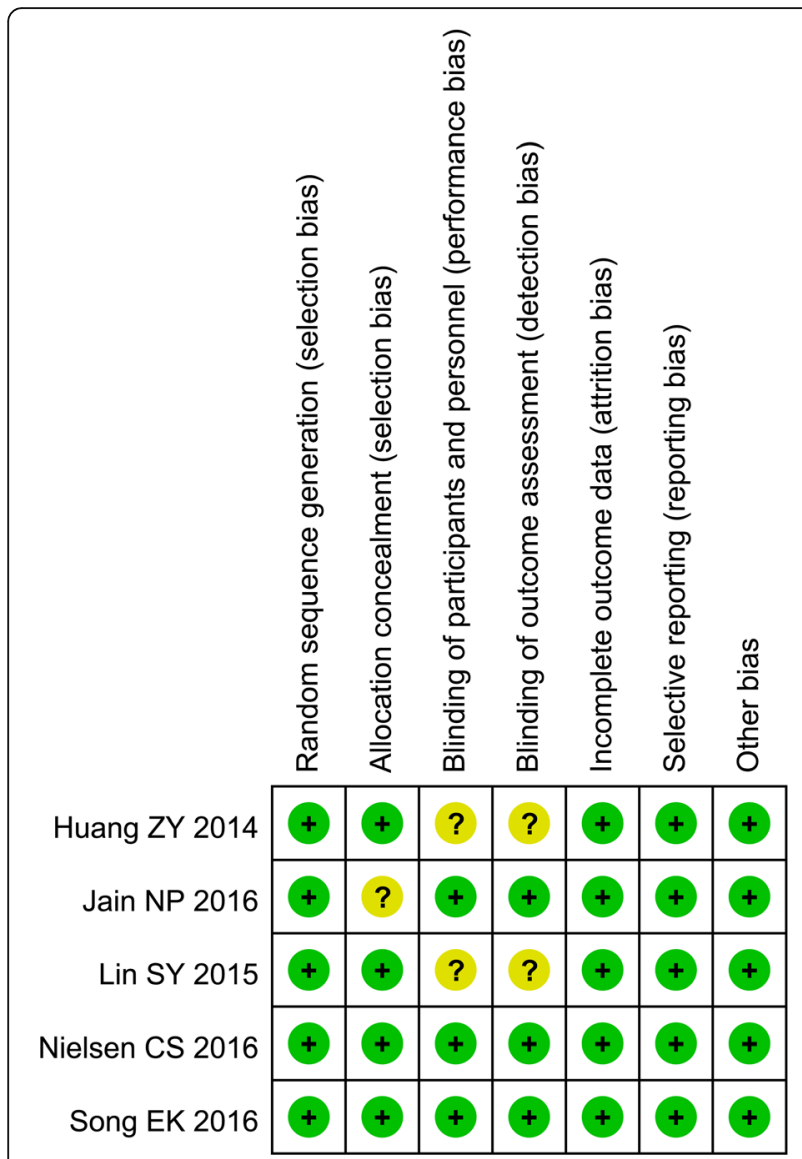

Fig. 2 Risk of bias summary

did not show detailed information of random sequence generation, and one trial [19] did not describe the methods of allocation concealment. Blinding of participants and personal (performance bias) were considered to be unclear in two trials $[15,16]$.

\section{Sensitivity and heterogeneity analysis}

There was significant heterogeneity for the impact of IV TXA application on total blood loss. The leaveone-out analysis showed that the key contributor to this high heterogeneity was one study conducted by Jain et al. [19]. After excluding it, heterogeneity was reduced to $I^{2}=73 \%$ for total blood loss. But significance of the pooled changes was not altered, which demonstrated that the results were robust.

\section{Total blood loss}

All of the studies provided the data of total blood loss. Three studies $[15,17,19]$ reported data of the combined group compared with the IV group, one study [16] reported data of the combined group compared with the IA group, and one study [20] reported data of the combined group compared with both the IV group and the IA group respectively. There was significant difference in terms of reducing total blood loss when comparing the combined group with the IV group $\left(\mathrm{chi}^{2}=18.44, I^{2}=84 \%, P<\right.$ $0.05)$ or the IA group $\left(\mathrm{chi}^{2}=1.35, I^{2}=26 \%, P<0.05\right)$ (Fig. 3).

\section{Blood volume of drainage}

Three studies $[15,16,20]$ provided data on blood volume of drainage. The result of the blood volume of drainage illustrated significant difference in the combined group when compared with the IV group (MD $-38.19,95 \%$ CI -63.31 to $-13.08, P<0.05, I^{2}=$ $0 \%)$. There was significant difference in blood volume of drainage between the combined group and the IA group (MD $-42.34,95 \% \mathrm{CI}-62.39$ to -22.30 , $P<0.05)$; however, this result should be interpreted with caution due to the presence of statistical heterogeneity $\left(\mathrm{chi}^{2}=7.17, I^{2}=86 \%\right)$ (Fig. 4).

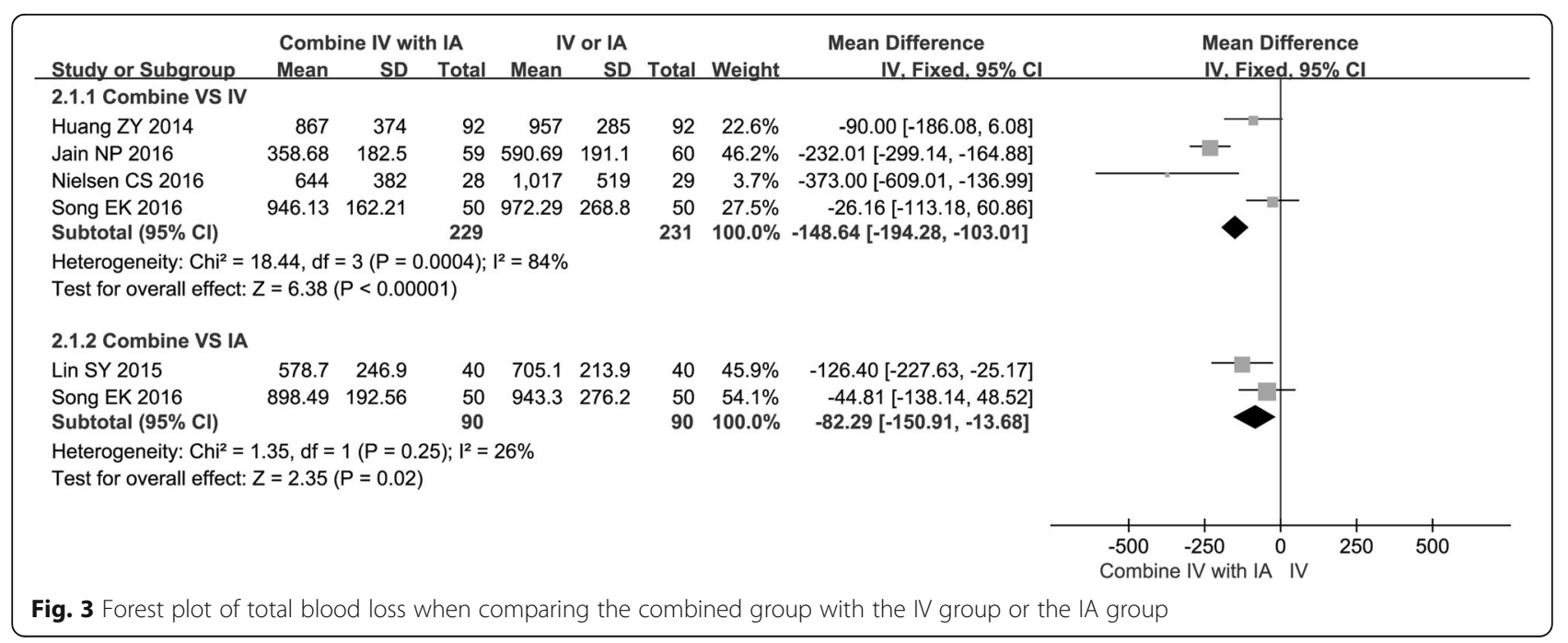




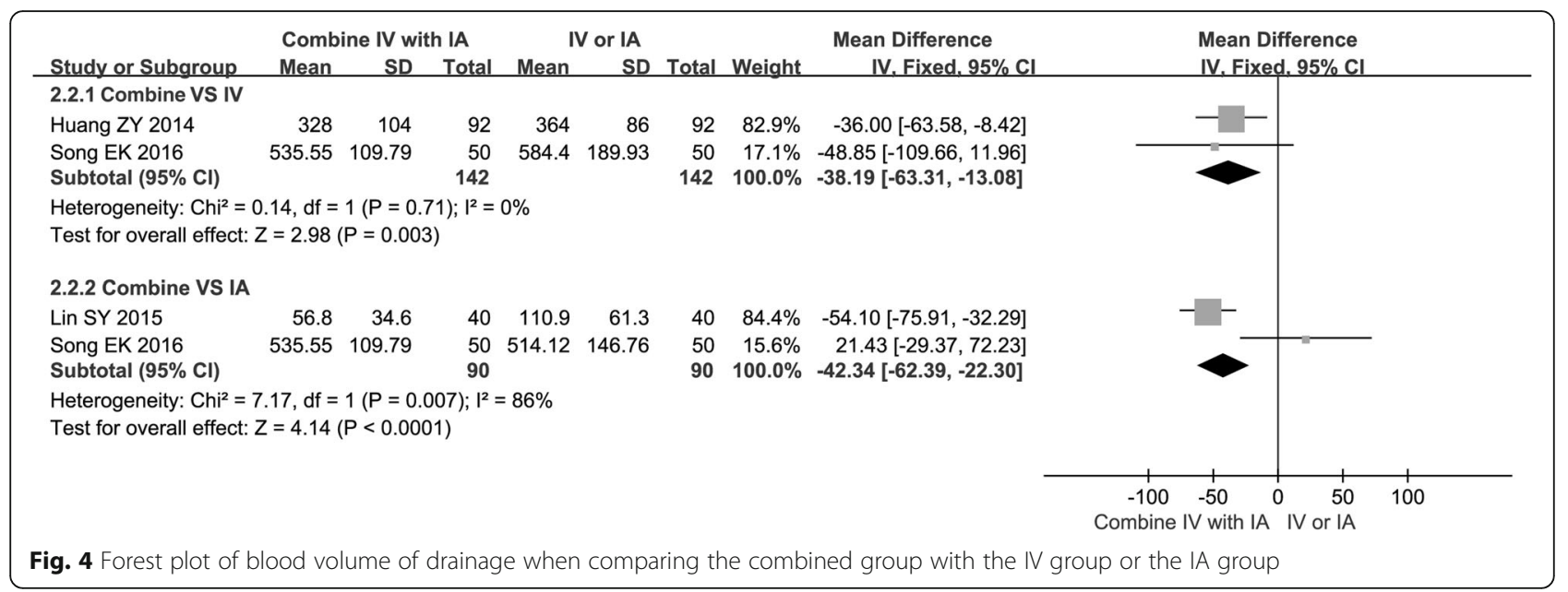

\section{Transfusion rate}

The data of transfusion rate was provided from all of the studies. There was no significant difference in transfusion rate when comparing the combined group with the IV or the IA group $\left(\mathrm{chi}^{2}=0.74, I^{2}=0 \%, P>0.05 ; \mathrm{chi}^{2}=\right.$ $0, I^{2}=0 \%, P>0.05$ ) (Fig. 5).

\section{Thromboembolic complications}

All of the studies provided data of thromboembolic complications. There was no significant difference in thromboembolic complications when comparing the combined group with the IV or the IA group. There was only one study that reported one case of DVT in the IV group [15]. Song [20] reported that there were three patients from the IV group and two patients from the combined group and one patient from the IA group had clinical suspicion of DVT based on calf swelling and tenderness. One case of clinical suspicion of DVT in the IV group was reported by Jain et al. [19] (Fig. 6).

\section{Discussion}

TXA is an antifibrinolytic agent which has been widely used today. Several studies have reported that IV administration of TXA can effectively reduce total blood on TKA [21]. Compared with IV TXA, the IA administration of TXA has the advantage of reaching to a maximum concentration of TXA at the bleeding site, and it is associated with low systemic absorption [22]. Considering the advantages of both IV TXA and IA TXA, it is logical to suggest that combined use of IV TXA and IA TXA is a more efficient method of reducing total blood loss. Karaaslan et al. [23] reported that combined use of

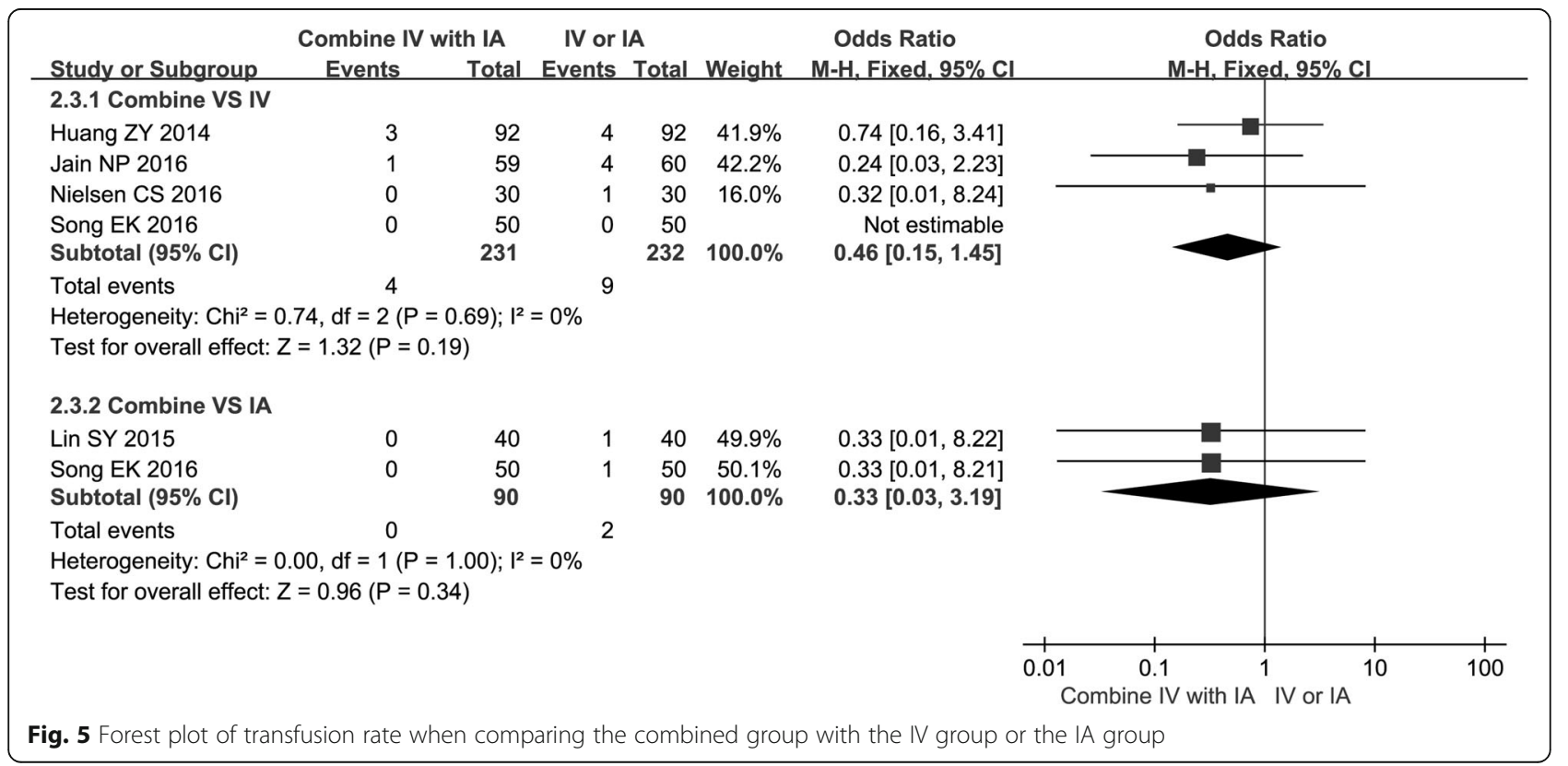




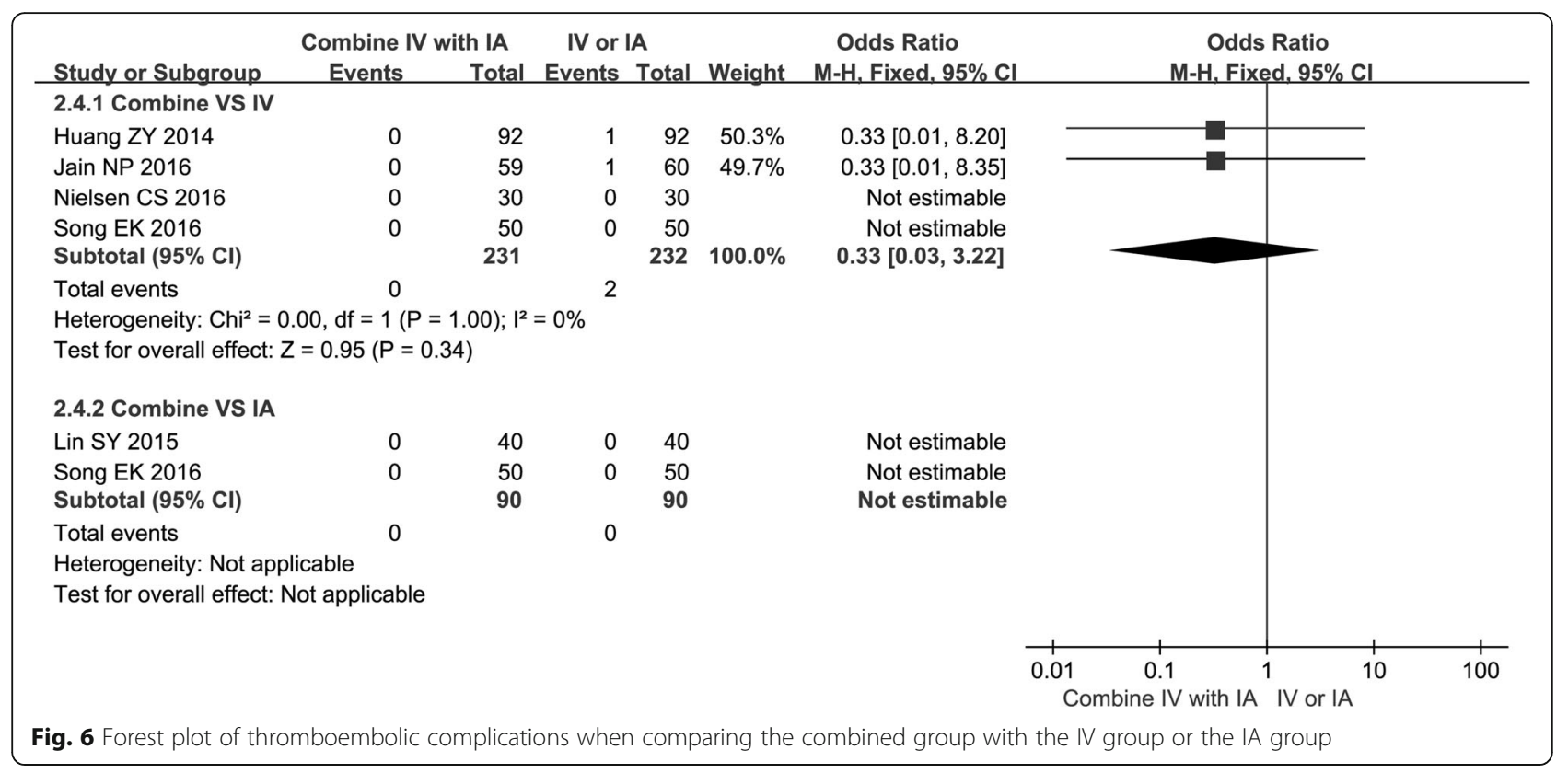

TXA in patients undergoing TKA can reduce blood loss with negligible side effects. Other studies $[15,16]$ that compared combined TXA with IV or IA TXA also reported that combined TXA was more effective than IV or IA TXA alone for patients undergoing TKA. In this meta-analysis, when compared with the IV group, we found that the combined group had reduced total blood loss by a mean of $-148.64 \mathrm{~mL}$ (CI -194.28 to -103.01 ), and when compared with the IA group, it reduced total blood loss by a mean of $-82.29 \mathrm{~mL}$ (CI -150.91 to -13.68). These results confirmed that combined TXA was more efficient for patients undergoing TKA in terms of reducing total blood loss.

Previous studies and several meta-analysis of IV TXA showed that administration of TXA intravenously reduced blood volume of drainage by up to $50 \%[12,24]$. Since IA administration of TXA can inhibit local activation of fibrinolysis and reduce time to vascular occlusion [25], it also has the advantage of limiting local blood loss [26]. Then, combined use of TXA has the advantages of both IV TXA and IA TXA in terms of reducing blood volume of drainage. Our meta-analysis also suggested that TXA administration that used the combination method resulted in a lower blood volume of drainage than TXA administration that used IV or IA alone $(-38.19$ and $-42.34 \mathrm{~mL}$, respectively, $P<0.05)$. Interestingly, there was a slightly higher transfusion rate in the combined group when compared with the IV or the IA group $(0.46,0.33$, respectively), even though there was no significant difference $(P>0.05)$. These results may be attributed to the fact that the transfusion criteria were inconsistent among these studies. In addition, a limited number of RCTs and patients may also lead to these results.
It is well known that patients undergoing TKA will take risks of DVT or PE [27, 28]. TXA has been widely used in TKA, while the risk of thromboembolic events are increasingly concerned [29]. Our meta-analysis had shown that there was no significant difference in thromboembolic complications when comparing the combined group with the IV or the IA group. This result was consistent with those studies that recommend the use of combined TXA on TXA $[15,19]$. One highly observable time of DVT or PE was the postoperative of TKA within 30 days [30], and chemoprophylaxis [31, 32] has been recommended to those patients. All of our studies observed the DVT or PE at least 30 days, and chemical prophylaxis was given to all patients or to those high-risk patients. Only one case of DVT was detected in the IV group 3 days after operation [15]. It should be noted that pneumatic tourniquet application could increase the risk of DVT or PE [33]. All patients reported by Huang et al. [15] used pneumatic tourniquet, and one case of DVT was detected in the IV group. In addition, Song [20] reported that three patients from the IV group, two from the combined group, and one patient from the IA group had clinical suspicion of DVT based on calf swelling and tenderness. Then, which one was the main reason for increased DVT or PE, TXA, or pneumatic tourniquet? The reason should be further confirmed. In addition, some included studies $[19,20]$ had evaluated symptomatic patients only, which may have caused a lower incidence of thromboembolic complications and missed the real patients who have DVT or PE. Considering the above factors, the results need to be further confirmed.

There was significant heterogeneity in the administration of IV TXA on total blood loss. The leave-one-out 
analysis showed that the key contributor to this high heterogeneity was one study conducted by Jain et al. [19]. After excluding this study, heterogeneity was reduced to $I^{2}=73 \%$ for total blood loss. By comparing these four studies that compared the combined group with the IV group, we found that the total blood loss in this study was calculated by hemoglobin balance method, whereas the total blood loss in other studies was calculated by gross formula [34]. Therefore, we infer that the calculation formula of total blood loss might be partly responsible for the heterogeneity.

There are several limitations in this meta-analysis. Firstly, the present meta-analysis focused only on papers published in English; the ones that were reported in other languages may increase heterogeneity and change the present results. Secondly, because four studies included subjects coming from Asia and one from Europe, the results cannot be extended to populations elsewhere. Besides, the dose and the timing of administrate IV TXA or IA TXA in the combined group were inconsistent among those studies. Further rigorously designed RCTs with larger sample sizes are needed to confirm the efficacy of combined TXA in primary TKA.

\section{Conclusions}

Present meta-analysis results demonstrated that combined use of TXA in TKA significantly reduce the total blood loss and blood volume of drainage without increasing the adverse effect of DVT or PE. Further studies are needed to investigate an appropriate dose and times of administering IV TXA combined with IA TXA in patients undergoing TKA.

\section{Abbreviations \\ IA: Intraarticular; IV: Intravenous; OA: Osteoarthritis; TKA: Total knee arthroplasty; TXA: Tranexamic acid}

\section{Acknowledgements}

Thanks are due to Wu Zhou for assistance with the analysis of the data and Xi Chen for valuable discussion.

\section{Funding}

No external funding was received for the initiation or completion of this study.

\section{Availability of data and materials}

Please contact author for data requests.

\section{Authors' contributions}

BM and $\mathrm{HL}$ conceptualized the study. YL and $\mathrm{OW}$ helped in the data curation. $\mathrm{KZ}$ and $\mathrm{HL}$ carried out the formal analysis. $J \mathrm{~L}$ and $\mathrm{QW}$ performed the investigation. BM and $Y L$ provided the methodology. BM and JL helped in the project administration. YL and KZ are responsible for the software. KZ supervised the study. $\mathrm{HL}$ and $\mathrm{QW}$ participated in the validation. GL wrote the original draft. BM and GL wrote, reviewed, and edited the paper. All authors read and approved the final manuscript.

\section{Competing interests}

The authors declare that they have no competing interests.

Consent for publication

Not applicable.
Ethics approval and consent to participate

Not applicable.

\section{Publisher's Note}

Springer Nature remains neutral with regard to jurisdictional claims in published maps and institutional affiliations.

\section{Author details}

'Department of Orthopedics, Union Hospital, Tongji Medical College, Huazhong University of Science and Technology, 1277, Jiefang Avenue, Wuhan, China. ${ }^{2}$ Department of Rheumatology, Tangdu Hospital, The Fourth Military Medical University, 1, Xinsi Avenue, Xi'an, China.

Received: 6 December 2016 Accepted: 30 March 2017

Published online: 18 April 2017

\section{References}

1. Visuri T, Makela K, Pulkkinen P, Artama M, Pukkala E. Long-term mortality and causes of death among patients with a total knee prosthesis in primary osteoarthritis. Knee. 2016;23:162-6. doi:10.1016/j.knee.2015.09.002.

2. Kim DH, Lee GC, Lee SH, Pak CH, Park SH, Jung S. Comparison of blood loss between neutral drainage with tranexamic acid and negative pressure drainage without tranexamic acid following primary total knee arthroplasty. Knee Surg Relat Res. 2016:28:194-200. doi:10.5792/ksrr.2016.28.3.194.

3. Seol YJ, Seon JK, Lee SH, et al. Effect of tranexamic acid on blood loss and blood transfusion reduction after total knee arthroplasty. Knee Surg Relat Res. 2016;28:188-93. doi:10.5792/ksrr.2016.28.3.188.

4. Liu JJ, Mullane P, Kates M, et al. Infectious complications in transfused patients after radical cystectomy. Can J Urol. 2016;23:8342-7.

5. Wang Q, Du T, Lu C. Perioperative blood transfusion and the clinical outcomes of patients undergoing cholangiocarcinoma surgery: a systematic review and meta-analysis. Eur J Gastroenterol Hepatol. 2016. doi;10.1097/ MEG.0000000000000706

6. Liu D, Dan M, Martinez MS, Beller E. Blood management strategies in total knee arthroplasty. Knee Surg Relat Res. 2016;28:179-87. doi:10.5792/ksrr. 2016.28.3.179.

7. Samujh C, Falls TD, Wessel R, et al. Decreased blood transfusion following revision total knee arthroplasty using tranexamic acid. J Arthroplasty. 2014; 29:182-5. doi:10.1016/j.arth.2014.03.047.

8. Shimizu M, Kubota R, Nasu M, et al. [The influence of tourniquet during total knee arthroplasty on perioperative blood loss and postoperative complications]. Masui. 2016;65:131-5.

9. Oremus K. Tranexamic acid for the reduction of blood loss in total knee arthroplasty. Ann Transl Med. 2015;3:S40. doi:10.3978/.j.ssn.2305-5839.2015.03.35

10. Rozen L, Faraoni D, Sanchez TC, et al. Effective tranexamic acid concentration for $95 \%$ inhibition of tissue-type plasminogen activator induced hyperfibrinolysis in children with congenital heart disease: a prospective, controlled, in-vitro study. Eur J Anaesthesiol. 2015;32:844-50. doi:10.1097/EJA.0000000000000316.

11. Charoencholvanich K, Siriwattanasakul P. Tranexamic acid reduces blood loss and blood transfusion after TKA: a prospective randomized controlled trial. Clin Orthop Relat Res. 2011;469:2874-80. doi:10.1007/s1 1999-011-1874-2

12. Tan J, Chen H, Liu Q, Chen C, Huang W. A meta-analysis of the effectiveness and safety of using tranexamic acid in primary unilateral total knee arthroplasty. J Surg Res. 2013;184:880-7. doi:10.1016/j.jss.2013.03.099.

13. Wong J, Abrishami A, El BH, et al. Topical application of tranexamic acid reduces postoperative blood loss in total knee arthroplasty: a randomized, controlled trial. J Bone Joint Surg Am. 2010;92:2503-13. doi:10.2106/JBJS.I. 01518.

14. Buntting C, Sorial R, Coffey S, et al. Combination intravenous and intraarticular tranexamic acid compared with intravenous only administration and no therapy in total knee arthroplasty: a case series study. Reconstructive Review. 2016:6:13-20. doi:10.15438/rr.6.2.138.

15. Huang Z, Ma J, Shen B, Pei F. Combination of intravenous and topical application of tranexamic acid in primary total knee arthroplasty: a prospective randomized controlled trial. J Arthroplasty. 2014;29:2342-6. doi:10.1016/j.arth.2014.05.026.

16. Lin SY, Chen CH, Fu YC, Huang PJ, Chang JK, Huang HT. The efficacy of combined use of intraarticular and intravenous tranexamic acid on reducing blood loss and transfusion rate in total knee arthroplasty. J Arthroplasty. 2015;30:776-80. doi:10.1016/j.arth.2014.12.001. 
17. Nielsen CS, Jans O, Orsnes T, Foss NB, Troelsen A, Husted H. Combined intra-articular and intravenous tranexamic acid reduces blood loss in total knee arthroplasty: a randomized, double-blind, placebo-controlled trial. J Bone Joint Surg Am. 2016;98:835-41. doi:10.2106/JBJS.15.00810.

18. Higgins JP, Thompson SG, Deeks JJ, Altman DG. Measuring inconsistency in meta-analyses. BMJ. 2003;327:557-60. doi:10.1136/bmj.327.7414.557.

19. Jain NP, Nisthane PP, Shah NA. Combined administration of systemic and topical tranexamic acid for total knee arthroplasty: can it be a better regimen and yet safe? A randomized controlled trial. J Arthroplasty. 2016;31: 542-7. doi:10.1016/j.arth.2015.09.029.

20. Song EK, Seon JK, Prakash J, et al. Combined administration of iv and topical tranexamic acid is not superior to either individually in primary navigated TKA. J Arthoplasty. 2016. doi:10.1016/j.arth.2016.06.052.

21. Akgul T, Buget M, Salduz A, et al. Efficacy of preoperative administration of single high dose intravenous tranexamic acid in reducing blood loss in total knee arthroplasty: a prospective clinical study. Acta Orthop Traumatol Turc 2016. doi;10.1016/j.aott.2016.06.007

22. Goyal N, Chen DB, Harris IA, Rowden NJ, Kirsh G, MacDessi SJ. Intravenous vs intra-articular tranexamic acid in total knee arthroplasty: a randomized, double-blind trial. J Arthroplasty. 2016. doi;10.1016/j.arth.2016.07.004.

23. Karaaslan F, Karaoglu S, Mermerkaya MU, Baktir A. Reducing blood loss in simultaneous bilateral total knee arthroplasty: combined intravenous-intraarticular tranexamic acid administration. A prospective randomized controlled trial. Knee. 2015;22:131-5. doi:10.1016/j.knee.2014.12.002.

24. Good L, Peterson E, Lisander B. Tranexamic acid decreases external blood loss but not hidden blood loss in total knee replacement. Br J Anaesth. 2003;90:596-9

25. Sperzel M, Huetter J. Evaluation of aprotinin and tranexamic acid in different in vitro and in vivo models of fibrinolysis, coagulation and thrombus formation. J Thromb Haemost. 2007;5:2113-8. doi:10.1111/j.1538-7836.2007.02717.x.

26. Gomez-Barrena E, Ortega-Andreu M, Padilla-Eguiluz NG, Perez-Chrzanowska $H$, Figueredo-Zalve R. Topical intra-articular compared with intravenous tranexamic acid to reduce blood loss in primary total knee replacement: a double-blind, randomized, controlled, noninferiority clinical trial. J Bone Joint Surg Am. 2014:96:1937-44. doi:10.2106/JBJS.N.00060.

27. Chotanaphuti T, Ongnamthip P, Silpipat S, Foojareonyos T, Roschan S, Reumthantong A. The prevalence of thrombophilia and venous thromboembolism in total knee arthroplasty. J Med Assoc Thai. 2007;90:1342-7.

28. Levy YD, Hardwick ME, Copp SN, Rosen AS, Colwell CJ. Thrombosis incidence in unilateral vs. simultaneous bilateral total knee arthroplasty with compression device prophylaxis. J Arthroplasty. 2013;28:474-8. doi:10.1016/j. arth.2012.08.002.

29. Izumi M, Migita K, Nakamura M, et al. Risk of venous thromboembolism after total knee arthroplasty in patients with rheumatoid arthritis. J Rheumatol. 2015;42:928-34. doi:10.3899/jrheum.140768.

30. Mantilla CB, Horlocker TT, Schroeder DR, Berry DJ, Brown DL. Risk factors for clinically relevant pulmonary embolism and deep venous thrombosis in patients undergoing primary hip or knee arthroplasty. Anesthesiology. 2003;99:552-60. 5A.

31. Odeh K, Doran J, Yu S, Bolz N, Bosco J, lorio R. Risk-stratified venous thromboembolism prophylaxis after total joint arthroplasty: aspirin and sequential pneumatic compression devices vs aggressive chemoprophylaxis. J Arthroplasty. 2016;31:78-82. doi:10.1016/j.arth.2016.01.065.

32. Mostafavi TR, Rasouli MR, Maltenfort MG, Parvizi J. Cost-effective prophylaxis against venous thromboembolism after total joint arthroplasty: warfarin versus aspirin. J Arthroplasty. 2015;30:159-64. doi:10.1016/j.arth.2014.08.018.

33. Mori N, Kimura S, Onodera T, Iwasaki N, Nakagawa I, Masuda T. Use of a pneumatic tourniquet in total knee arthroplasty increases the risk of distal deep vein thrombosis: a prospective, randomized study. Knee. 2016;23:887-9. doi:10.1016/j.knee.2016.02.007.

34. Kvederas G, Porvaneckas N, Andrijauskas A, et al. A randomized doubleblind clinical trial of tourniquet application strategies for total knee arthroplasty. Knee Surg Sports Traumatol Arthrosc. 2013;21:2790-9. doi:10.1007/s00167-012-2221-1.

\section{Submit your next manuscript to BioMed Central and we will help you at every step:}

- We accept pre-submission inquiries

- Our selector tool helps you to find the most relevant journal

- We provide round the clock customer support

- Convenient online submission

- Thorough peer review

- Inclusion in PubMed and all major indexing services

- Maximum visibility for your research

Submit your manuscript at www.biomedcentral.com/submit
Biomed Central 